\title{
Fallacies in Ad Hominem Arguments ${ }^{1}$
}

\author{
Falacias en argumentos ad Hominem
}

\author{
Christian Dahlman \\ Faculty of Law, Lund University, Lund, Sweden \\ Christian.Dahlman@jur.lu.se \\ David Reidhav \\ Faculty of Law, Lund University, Lund, Sweden \\ David.Reidhav@jur.lu.se \\ Lena Wahlberg \\ Faculty of Law, Lund University, Lund, Sweden \\ Lena.Wahlberg@jur.lu.se
}

Received: 25-07-2011 Accepted: 14-12-2011

\begin{abstract}
Arguments ad hominem are common in political debates, legal argumentation and everyday conversations. In this article, we propose a general definition of ad hominem arguments. An argument ad hominem is an argument that makes a claim about the reliability of a person in the performance of a certain function, based on some attribute relating to the person in question. On the basis of this definition, we examine the different ways that ad hominem arguments can go wrong, and classify them as seven different ad hominem fallacies: false attribution, irrelevant attribute, overrated effect, reliability irrelevance, irrelevant person, insufficient degree and irrelevant function. The various fallacies are illustrated with examples from politics, law and everyday life.
\end{abstract}

Keywords: Ad hominem, fallacy, argumentation, personal attack, reliability, testimony.

${ }^{1}$ The research presented in this article was funded by Torsten och Ragnar Söderbergs Stiftelser. We owe thanks to Niklas Arvidsson, Roberta Colonna Dahlman, Eveline Feteris, Åke Frändberg, Tobias Hansson Wahlberg, Patricia Mindus, Antonino Rotolo, Stefan Schubert, Torben Spaak, Lennart Åqvist and two anonymous referees for helpful comments on earlier drafts. 
Resumen: Los argumentos ad hominem son comunes en debates políticos, en la argumentación legal y las conversaciones cotidianas. En este trabajo, proponemos una definición general de argumentos ad hominem. Un argumento ad hominem es un argumento que mantiene una pretensión sobre la confiabilidad de la persona en el ejercicio de cierta función, basada en algunos atributos relacionados con la persona en cuestión. Sobre la base de esta definición, examinamos las diferentes formas de los argumentos ad hominem que pueden ser defectuosos, y los clasificamos en siete diferentes falacias ad hominem: atribución falsa, atribución irrelevante, efecto de sobreestimación, irrelevancia de confiabilidad, persona irrelevante, grado irrelevante y función irrelevante. Estas falacias son ilustradas con ejemplos de la política, la ley y la vida cotidiana.

Palabras clave: Ad hominem, falacia, argumentación, ataque personal, confiabilidad, testimonio.

\section{Introduction}

One of the most common ways to argue against a claim is to attack it indirectly, by attacking the person who makes the claim. Examples are easy to find in political debates, courtrooms and dinner conversations. A politician who claims that the government should cut taxes is countered with the argument that he endorses tax cuts because it would benefit him personally. The testimony of an eye witness in a murder trial is attacked by the defense attorney, with the argument that the witness is unreliable because he is a drug addict. A guest at a dinner party who says that people in rich countries should do more for the people in poor countries is met with the argument that she does not do much for poor people herself.

Counter arguments of this kind are usually dismissed as bad arguments. They are rejected as unfair and irrelevant, and it is said that they commit the ad hominem fallacy. This reaction gives rise to questions. Are these arguments always fallacious? Is the attack always aimed at the opposing arguer in the discussion? Are all arguments that commit the ad hominem fallacy fallacious in the same way? Our answer to each of these three questions is negative. An ad hominem argument is not always fallacious. Some ad hominem arguments attack a person who is not a participant in the discussion. And the ad hominem arguments that are fallacious can commit a number of different fallacies. This article will explain and develop these views. 
That an argument which seeks to undermine a claim by attacking the person who makes the claim is not always fallacious has been pointed out by many other scholars. It can, for example, make good sense to challenge the testimony of an eye-witness with the observation that the witness is almost blind. If a speaker claims that she should be relied on, it becomes relevant to challenge that claim with an argument that attacks her reliability. Some authors, including John Woods (2010, p. xxv), Douglas Walton (1998, p. 125), Alan Brinton (1995, p. 215) and Bruce Waller (2005, pp. 180-192), say that this shows that an argument ad hominem is not always fallacious. In their treatment of ad hominem arguments, there are ad hominem arguments that are legitimate and ad hominem arguments that commit the ad hominem fallacy. Others, notably Irving Copi and Carl Cohen (2002, pp. 143-145), prefer to reserve the term ad hominem for arguments that commit the ad hominem fallacy: If an argument is not fallacious it is not an ad hominem argument. This difference in terminology can be confusing, and it is important to bear in mind that it does not reflect a substantial disagreement over legitimacy. Like Woods, Walton, Brinton and Waller we prefer to distinguish between ad hominem argument and ad hominem fallacy. We therefore begin our investigation by developing a general definition of ad hominem argument. We then move on to investigate the conditions under which these arguments are fallacious.

Our approach to ad hominem arguments differs from the standard approach taken in textbooks on fallacies. The main structure in the standard approach is the division of ad hominem arguments in the subtypes known as abusive ad hominem and circumstantial ad hominem, along with the additional subtype known as tu quoque. Our approach is structured around a general definition: an argument ad hominem is an argument that points out that a person has a certain attribute and claims that this affects the reliability of the person with regard to the performance of a certain function. In the following, we will relate our framework to the standard classification at appropriate points.

In our account, an ad hominem argument does not necessarily attack the opposing arguer in the discussion. A personal attack on someone who does not participate in the discussion is also an ad hominem argument. Such attacks are often used as counter arguments against an authority argument. Think, for example, of a discussion where one of the participants 
backs up his claim by referring to Professor $\mathrm{X}$ as an authority, and the other participant replies with a personal attack against Professor X, intended to undermine the Professor's reliability as an authority. In our understanding this is clearly an argument ad hominem, but there are scholars who have a different view. According to Frans van Eemeren, Rob Grootendorst and other members of the pragma-dialectical school this kind of argument does not count as an argument ad hominem, as it attacks a person outside the discussion. According to their definition, an argument ad hominem is an argument that violates the first rule of discussion, that "parties must not prevent each other from advancing standpoints or casting doubt on standpoints" (see, e.g., van Eemeren and Grootendorst, 1992, pp. 153-155). In our view, this makes the analysis of ad hominem arguments too narrow. As we understand it, the soundness of a personal attack depends on a number of factors, but participation in the discussion is not one of them. It makes no difference for the soundness of the argument whether the person under attack is a participant in the discussion or not.

In our analysis, an argument that commits the ad hominem fallacy can be fallacious in seven different ways. We will identify each of these errors and analyze them as seven separate ad hominem fallacies. This means that our account of how ad hominem arguments can be fallacious is broader than the exposition you would find in most textbooks. It is often said that ad hominem arguments are fallacious because they try to attack a claim by attacking the reliability of the person who makes the claim, in spite of the fact that this is irrelevant to the correctness of the claim (see, e.g., Hamblin, 1970, p. 41; Walton, 1987, p. 317; Copi and Cohen, 2002, p. 143). In our account, this is just one of the seven ways in which an ad hominem argument can be fallacious. It will be analyzed in section three as "the fallacy of reliability irrelevance".

At the outset, our approach is similar in some ways to Brinton's treatment of ad hominem arguments. Like Brinton we seek to identify different ways in which ad hominem arguments can go wrong. An important difference between our approach and Brinton's is that we analyze all these errors as false premises. As we shall see, we represent ad hominem arguments as deductively valid arguments and understand every ad hominem fallacy in terms of a false premise. This approach is somewhat unorthodox. The ad hominem fallacy is normally assumed to involve an illegitimate move from 
premise to conclusion. It is important to understand, however, that this difference is a matter of presentation. To describe an ad hominem fallacy as a false premise instead of an illegitimate move from premise to conclusion is just a different way of describing the same thing. To see this, consider the following reasoning: "What the witness says is not true. He is an alcoholic." This might be held to commit an ad hominem fallacy because it makes an illegitimate move from premise to conclusion: the conclusion (what the witness says is not true) cannot be derived from the premise (the witness is an alcoholic). A different way to say the same thing is to say that the argument is fallacious because the premise that would make it legitimate (what an alcoholic says is not true) is false. It is exactly because this premise is false that some scholars say that we are dealing with an illegitimate move from premise to conclusion.

We believe our approach has several advantages. By conceptualizing every ad hominem error as the result of a false premise we are able to give a uniform treatment of the various ways in which ad hominem arguments can go wrong. We are also in a position to classify these errors not only on basis of which premise of the argument is false, but also in terms of the grounds on which the premise is false. This makes it possible to give a comprehensive and detailed description of the various forms of error.

\section{Definition of Argument ad Hominem}

We propose the following general definition: an argument ad hominem is an argument that makes a claim about the reliability of a person, $\mathrm{P}$, based on an attribute, $\mathrm{A}$, of $\mathrm{P}$. The argument points out that $\mathrm{P}$ has $\mathrm{A}$, and it claims that, because $\mathrm{P}$ has A, P's reliability in the performance of a certain function, $\mathrm{F}$, amounts to the degree $\mathrm{D}$. Ad hominem argumentation, in its basic form, can be represented as follows.

Argument ad hominem (basic form):

(i) $P$ has $A$

(ii) If $P$ has $A$, the reliability of $P$ in the performance of $F$ is $D$

(iii) The reliability of $P$ in the performance of $F$ is $D$ 
We will speak of the first premise as the attribution premise and the second premise as the effect premise.

As is indicated by the term "ad hominem" $\mathrm{P}$ is a person. However, traditionally, arguments in which $\mathrm{P}$ is a group of people or an organization have been categorized as ad hominem as well, and we see no reason to break with this tradition. By "attribute" we mean a property, in the widest sense of the term, which can be ascribed to the person P. An attribute can, for example, consist in having bad eyesight, being a compulsive liar or being in Lund. Some of the things we here call attributes are normally referred to, not as attributes or properties, but rather as "circumstances". For example, the fact that a witness was in Lund at a certain time would be described by lawyers as a "circumstance". However, in order to maintain a coherent terminology, we will treat any fact that can be ascribed to a person as an attribute.

An argument ad hominem is an argument about reliability. It is an argument claiming that a certain attribute has a certain effect on a person's reliability. This is not always apparent when one looks at the way ad hominem arguments are described, but a number of other scholars who describe the effect of ad hominem arguments regard them broadly in these terms. Thus Brinton (1985, p. 56) says ad hominem arguments typically question someone's credentials as a speaker, and Walton (1998, pp. 273-278) observes that they seek to affect the opponent's "credibility". ${ }^{2}$

Reliability depends on ability as well as motivation. That a person is reliable in the performance of a function means that he or she is able to perform the function and motivated to do so. A witness, for example, is reliable when he or she has the cognitive ability to observe and remember events correctly as well as the motivation to tell the truth. As we shall see, some ad hominem arguments are aimed at ability while others are aimed at motivation.

According to our definition ad hominem arguments target P's reliability with respect to a certain function, F. In this formulation F can stand for

${ }^{2}$ That the arguments we are interested in are fundamentally about reliability was detected by Bentham. He does not use the term ad hominem at all. Instead he speaks of arguments that commit this kind of fallacy as modifications of the "fallacy of distrust" (1824/1952, pp. 83-92; pp. 100-102). 
any function that a person can be relied upon to fulfill. It can stand for the function of serving as an eyewitness in a court of law, but it can just as well stand for the function of being Prime Minister. This makes our account of ad hominem argument broader than Brinton's. Brinton (1995, pp. 213-215) describes an argument ad hominem as an argument that attacks someone's reliability as an advocate. In our account, F can stand for the function of advocating a certain proposition, but it can also stand for other functions that can be related to reliability. When $\mathrm{F}$ is the Prime Ministerial function, it stands for confidence in $\mathrm{P}$ to exercise good judgment on political issues. When $\mathrm{F}$ is the function of serving as an eye witness, it stands for reliability to give an accurate account of certain events. In our account "credibility" (i.e. reliability as a source of information) is thus a sub-class of reliability in the performance of function. ${ }^{3}$

An argument that is not about reliability is not an argument ad hominem. The argument that Pedro is older than me because he was born in 1956 is not an argument ad hominem. Being older than someone is not a question of reliability. In some cases, it is a matter of interpretation whether an argument is an argument about reliability. Consider the argument "Alfred can't run fast. He has a bad leg”. This is not necessarily an argument about reliability, but it can be interpreted as such. It can be interpreted as an argument to the effect that Alfred cannot be relied on to run fast. We could, for example, imagine that Alfred is being considered for the position of courier. Someone is needed to deliver an important message before a certain time. As we all know, interpretation is difficult. For present purposes this need not worry us. That an argument ad hominem is an argument about reliability simply means that an argument that is interpreted as an argument ad hominem is an argument that is interpreted as an argument about reliability.

The effect that A has on P's reliability can be positive or negative: it can

${ }^{3}$ According to Brinton arguments directed at functions which are merely accidentally associated with human beings are not ad hominem. He concludes (1995, pp. 213-214) that only arguments directed at advocacy qualify as ad hominem arguments. Given the structural similarities of arguments about reliability in the performance of functions of all kinds, an account which is applicable to any of these functions is in our view methodologically preferable. Besides, we are not convinced that advocacy is an essential attribute for being a person, as Brinton assumes. 
improve P's reliability, or it can or reduce it. We will talk about arguments where the effect is positive as positive ad hominem arguments and arguments where the effect is negative as negative ad hominem arguments.

Ad hominem arguments are often used as counter-arguments to claims about P's reliability. They are therefore often defined as counter-arguments. In our view, this makes the analysis too narrow. Given our definition, an ad hominem argument does not need to be a counter-argument. As we have seen above, the ad hominem argument in its basic form is an argument in its own right. The claim that it makes about P's reliability need not stand in opposition to some other claim about P's reliability.

An ad hominem argument that targets a particular claim, and which draws the conclusion that the effect that A has on P's reliability makes this target claim false, can be represented as an extension of the ad hominem argument in its basic form.

Argument ad Hominem (extended form):

(i) $P$ has $A$

(ii) If $P$ has $A$, the reliability of $P$ in the performance of $F$ is $D$

(iii) If the reliability of $P$ in the performance of $F$ is $D$, the target claim is false

(iv) The target claim is false

The ad hominem argument in its extended form has three premises: the attribution premise and the effect premise from the basic form, plus a third premise that we shall label the rebuttal premise.

The following dialogue serves as an example.

$\mathrm{X}$ : "Mrs. Borg is very reliable as an eyewitness."

Y: "No, she is not. She has poor eyesight."

The argument advanced by $\mathrm{Y}$ is an ad hominem in the extended form. It is a counter-argument to the claim that Mrs. Borg is very reliable, and it draws the conclusion that the target claim is false. In full, the argument of $\mathrm{Y}$ in the dialogue is: 
(i) Mrs. Borg has poor eyesight.

(ii) If Mrs. Borg has poor eyesight, the reliability of Mrs. Borg as an eye witness is low.

(iii) If the reliability of Mrs. Borg as an eye witness is low, the claim "Mrs. Borg is very reliable as an eye witness" is false.

(iv) The claim "Mrs. Borg is very reliable as an eye witness" is false.

\section{Ad Hominem Fallacies}

An argument ad hominem can go wrong in many different ways. We shall now identify seven kinds of error. We talk about these errors as ad hominem fallacies, and we refer to them by the following names.

1. the fallacy of false attribution

2. the fallacy of irrelevant attribute

3. the fallacy of overrated effect

4. the fallacy of reliability irrelevance

5. the fallacy of irrelevant person

6. the fallacy of insufficient degree

7. the fallacy of irrelevant function

Each fallacy results from the presence of a false premise in the ad hominem argument. An argument that commits the fallacy of false attribution is unsound because the attribution premise is false. In arguments committing the fallacy of irrelevant attribute or overrated effect the effect premise is false. Arguments that commit the fallacy of reliability irrelevance, irrelevant person, insufficient degree or irrelevant function have a false rebuttal premise. In its basic form ad hominem argumentation can commit only the first three fallacies. Since the last four fallacies consist in a false rebuttal premise, they cannot be committed by arguments in the basic form. Ad hominem arguments in the extended form, on the other hand, can commit any of the seven fallacies.

The fallacy offalse attribution is committed when the argument claims that $\mathrm{P}$ has an attribute $\mathrm{P}$ in fact lacks. Here is an example. 
"Barack Obama shouldn't be trusted as Commander in Chief. He is a Muslim, you know."

The fallacy of irrelevant attribute is committed in cases when A has no effect on P's reliability in the performance of F. Here is an obvious example.

"You cannot take him seriously as an expert on foreign policy. He looks like an aardvark."

This kind of error in ad hominem arguments is also identified by Woods (2010, pp. 98, 105). As the example shows, sometimes a negative ad hominem argument that commits the fallacy of irrelevant attribute is not only a bad argument, but a downright insult. And indeed arguments of this kind are classified as "abusive" ad hominem arguments by Copi and Cohen (2002, p. 143). However, the fallacy of irrelevant attribute is not always abusive. It is not abusive in positive ad hominem arguments, of course, and there are cases where a negative ad hominem argument commits the fallacy of irrelevant attribute without being abusive. Consider the following example.

"It is true that Mr. Berg has testified that the plaintiff was bleeding, but we should not rely too much on this testimony, since Mr. Berg is not a medical expert."

This argument commits the fallacy of irrelevant attribute (you do not need to be a medical expert to recognize that someone is bleeding), but it is not abusive. The mere observation that someone is not a doctor is not an insult.

The effect of an attribute depends on the context (see, e.g., Walton, 1987, p. 323). In this article, we treat context as a bundle of attributes. An ad hominem argument must be understood as being made relative to an assumption about a certain bundle of attributes that includes A. This bundle determines the effect that the attribute is assumed to have on P's reliability. We propose to label this bundle $\mathrm{B}_{\mathrm{AH}}$. Note that this is the assumed context, and that it may not correspond with the actual context. For example, the argument might be made on the mistaken assumption that a person has poor eyesight. Given this mistaken assumption, the effect of the circumstance that the eyewitness was not close to the scene of the crime (A) is likely to be overrated. 
We use the label $\mathrm{B}_{\mathrm{A}}$ for the bundle of attributes that actually holds for P. On our account this actual context determines the real effect of A on P's reliability. It is against the background of $\mathrm{B}_{\mathrm{A}}$ that an ad hominem argument should ideally be assessed. In other words, a fallacy can occur because reliability is assessed on the basis of a non-actual bundle of attributes, or because the relevance of $\mathrm{A}$ in the actual bundle is estimated inaccurately by the arguer.

The following sets of relationships-between A, the degree of reliability in a particular function $\mathrm{F}$, and a particular person $\mathrm{P}$ with his or her actual bundle of attributes $\left(\mathrm{B}_{\mathrm{A}}\right)$ including $\mathrm{A}$ - are conceivable.

(a) The attribute A never affects the reliability of a person in the performance of $\mathrm{F}$ and therefore does not affect the reliability of the particular person $\mathrm{P}$ in the actual context $\mathrm{B}_{\mathrm{A}}$.

(b) The attribute A sometimes affects the reliability of a person in the performance of $\mathrm{F}$, but does not affect the reliability of the particular person $\mathrm{P}$ in the actual context $\mathrm{B}_{\mathrm{A}}$.

(c) The attribute A sometimes affects the reliability of a person in the performance of $\mathrm{F}$, and the particular person $\mathrm{P}$ in the actual context $\mathrm{B}_{\mathrm{A}}$ represents a case where A has such an effect.

(d) The attribute A always affects the reliability of a person in the performance of $\mathrm{F}$ and therefore affects the reliability of the particular person $\mathrm{P}$ in the actual context $\mathrm{B}_{\mathrm{A}}$.

It can be questioned whether there really are attributes that never affect the reliability of $\mathrm{P}$ in performing $\mathrm{F}$. If, however, A never is relevant, it will be irrelevant irrespective of other attributes that $\mathrm{P}$ has. For example, if the color of the clothes of the person testifying is never relevant to the assessment of that person's reliability as a source of information, it does not matter what other attributes the person has. In any situation of the sort described in (a) an ad hominem argument to the effect that $\mathrm{A}$ is relevant will commit the fallacy of irrelevant attribute.

The fact that a fallacy is being committed is easy to spot in cases where it is unthinkable, or at least highly implausible, that the attribute that is pointed out could ever affect a certain kind of reliability: an example would be the attribute of an expert on foreign policy looking like an aardvark. It is 
more difficult to spot when the argument points to an attribute that is relevant in some contexts but not in the one at hand (situation (b) above). For example, not wearing one's glasses normally affects a person's reliability as an eyewitness. However, the fact that $\mathrm{P}$ was not wearing her glasses is an irrelevant attribute for her reliability as an eye witness if she has perfect vision and wears glasses as a fashion accessory.

The fallacy of overrated effect is committed in cases where A has an effect on P's reliability in performing $\mathrm{F}$ but this effect is less than the effect premise claims. The argument does not commit the fallacy of irrelevant attribute, as it points to an attribute that is relevant to the reliability issue at hand. What is wrong in the argument is simply that it exaggerates the effect of the attribute. This error has also been identified by Brinton as one of the ways that ad hominem arguments can go wrong. Brinton describes it as a "failure in degree of support" (1995, p. 218).

An example of the fallacy of overrated effect in legal argumentation occurs in the Swedish case NJA 1986 s. 358. A man, TS, reported to his insurance company that his car had been stolen and claimed compensation for his loss in accordance with the insurance policy. The company did not believe his story and refused to pay. TS sued. The company argued, before the court, that TS should be considered unreliable because he had a criminal record: TS had previously been convicted for several crimes, including attempted insurance fraud. This argument is clearly ad hominem. The company claimed that the conviction for insurance fraud had a strong negative effect on TS's reliability to give accurate testimony. This negative ad hominem was not accepted by the appellate court. Confirming that TS's criminal record did indeed have a negative effect on his reliability, but emphasizing that many years had passed since the last conviction, the court held that the effect was less significant than the insurance company had argued. The appellate judges were, in effect, insisting that the ad hominem argument presented by the insurance company committed the fallacy of overrated effect.

The fallacy of overrated effect can occur in situations (c) and (d) above. This fallacy-like the fallacy of irrelevant attribute-can be the result of the reliability being assessed relative to a non-actual bundle of attributes or an inaccurate estimate of the effect of the bundle by the arguer. Thus, in the example from the Swedish Supreme Court the insurance company based 
their reliability assessment on an incompletely specified (and in this sense non-actual) bundle in which the time-span between the conviction and the compensation claim was not included.

Some ad hominem arguments claim that the attribute they invoke categorically disqualifies $\mathrm{P}$ from reliable performance of $\mathrm{F}$. Consider, for example, the following argument.

"There is just one thing you need to know about the next witness. She is the mother of the accused. As we all know, a mother would say anything to protect her son. You should therefore disregard everything she has to say. No other thing that you learn about her could ever change that."

This kind of argumentation is sometimes referred to as poisoning the well (see, e.g., Walton, 2006, p. 289). Where it is claimed that A renders $\mathrm{P}$ completely unreliable, no matter what other attributes $P$ has, the situation is of kind (d). Plainly, any claim imputing complete unreliability will be a very strong one, and even when the situation indeed is of kind (d) this kind of argumentation often involves the fallacy of overrated effect.

An attribute's effect on reliability depends, not just on the bundle, but also on the function at issue. The fallacies of irrelevant attribute and overrated effect can therefore occur if information about an attribute's effect on reliability in the performance of one function is unwarrantedly generalized or extrapolated to another function. This mistake is not uncommon in assessments of the credibility of expert witnesses.

The fallacy of reliability irrelevance is committed when the effect that A has on P's reliability does not make the target claim false, because the target claim is not about reliability. Consider the following example.

X: "The government should cut taxes. It would be good for the economy." Y: "You're just saying that because you would benefit from tax cuts."

The argument advanced by $\mathrm{X}$ has an unstated major premise to the effect that the government should cut taxes if tax cuts would be good for the economy, a minor premise affirming that tax cuts would be good for the economy, and the conclusion that the government should cut taxes. None of these three claims are about X's reliability. Y may well be right when he says that $\mathrm{X}$ is making the argument because tax cuts would benefit him per- 
sonally, but that does not falsify any claim in X's argument, and therefore does not affect its soundness.

The fallacy of reliability irrelevance is a special case of the fallacy known as ignoratio elenchi (cf. Walton, 1998, p. 65). It presents an argument on an issue as a counter-argument to a claim on a different issue. This fallacy is sometimes used deliberately, with rhetorical intent, to divert attention from the main argument and shift discussion to a different issue (van Eemeren and Grootendorst, 1992, pp. 152-153). The latter is sometimes referred to as a red herring.

It should be noted that an argument that is not about reliability can be backed up by an argument about reliability. This means that an ad hominem argument that commits the fallacy of reliability irrelevance in relation to a certain argument could be a legitimate counter-argument against a backing argument. Consider the following dialogue.

X: "The government should cut taxes. It would be good for the economy."

Y: "I'm not sure. I don't understand that much about economics."

$\mathrm{X}$ : "You can trust me. I have a PhD in economics. That should make me reliable as an expert on the economic impact of tax cuts."

Y: "Sorry. You would also benefit from tax cuts, and therefore you're not reliable as an expert on the economic impact of tax cuts."

$\mathrm{X}$ is now backing up the main argument with an authority argument. He says he is a reliable expert on the economic impact of tax cuts because he has a $\mathrm{PhD}$ in economics. This is a positive ad hominem argument. The argument advanced by $\mathrm{Y}$ is also an ad hominem argument-a negative one that stands as a counter-argument to the positive argument advanced by X. This second argument targets the conclusion in X's ad hominem argument and says that this conclusion makes a false claim. In this way, the counterargument adds another attribute, X's personal interest in tax cuts, to the bundle and claims that X's credibility, given his doctoral qualification and this additional attribute, differs considerably from his credibility given the doctoral qualification alone. Since the negative ad hominem argument invoked by $\mathrm{Y}$ draws the conclusion that X's claim about his own reliability is false, Y's argument is an ad hominem argument in the extended form. This argument does not commit the fallacy of reliability irrelevance. 
Here lies the crucial difference between Y's response that X would benefit personally from tax cuts when we regard it as a counter-argument to X's backing argument and the same response when we regard it as a counterargument to X's main argument. As we saw above, the response commits the fallacy of reliability irrelevance against the main argument. This shows the importance of picking the right target claim. An ad hominem argument committing the fallacy of reliability irrelevance vis-à-vis one claim can be perfectly sound as a counter-argument to another claim.

Notice that this makes it difficult to assess ad hominem arguments in many of their applications to actual events and issues. In real life it is often unclear what the target claim is. If the rebuttal premise is such that it would come out false if the argument is taken to target one claim and true if it is taken to target another, the soundness of the argument may be equally unclear. This only goes to show that if we are to determine whether an argument is successful, it must be clear what the argument is meant to target.

Some scholars have suggested that ad hominem arguments do not commit a fallacy of irrelevance when there is doubt about the truth of a premise invoked by the opposing arguer. Lawrence Hinman (1982, p. 339) presented this idea in the early 1980s, and a similar argument has recently been made by Christopher Johnson (2009, pp. 256-259). When there is doubt about the truth of a premise invoked by the opposing arguer it is not irrelevant, their argument goes, to question whether the opposing arguer should be relied on in his claim that the premise is true. There is some truth in this observation, but it overlooks the fact that a counter-argument will always have a specific target, and it fails to separate counter-arguments that target a claim in the main argument from counter-arguments to a claim in the backing argument. That an ad hominem argument is relevant as a falsifier against a claim in a backing argument does not mean that it is relevant as a falsifier against a claim in the main argument. The ad hominem argument will still commit the fallacy of reliability irrelevance against the main argument if the main argument is not about reliability.

One type of argument that commits the fallacy of reliability irrelevance is the argument known as tu quoque. The standard treatment of ad hominem arguments identifies tu quoque as a special kind of ad hominem fallacy. Tu quoque is a counter-argument to the argument that a certain way of acting is wrong which attacks the opposing arguer by pointing out that he has acted in that very way. 
An interesting example can be taken from the Nuremberg Trials (see, Yee, 2004, pp. 103-116; Heise, 2009, pp. 10-14). The German Admiral Karl Dönitz was accused of unrestricted submarine warfare in violation of the London Naval Treaty of 1936, to which Germany was a party. Dönitz had ordered his submarines to attack British merchant vessels without warning. Before the court, Dönitz made the counter-argument that allied submarines had done the same thing. For example, the American Admiral Chester Nimitz had torpedoed Japanese merchant vessels without warning. This is an argument ad hominem, although in this case the opposing arguer being responded to is not a person but rather a group of people that he represents. The argument challenges the reliability of the allies to pass judgment on the unrestricted submarine warfare ordered by Dönitz.

The tribunal found Dönitz guilty on the charge of illegal submarine warfare. This can be taken to show that the tribunal recognized the tu quoque argument as fallacious. It should be mentioned, however, that no sentence was imposed on Dönitz for this crime, in addition to his sentence for other crimes. This strange decision suggests that the tribunal was, to some degree, taken in by the argument.

The fallacy of irrelevant person is committed when the target argument is about someone's reliability, but that person is not P. An argument that commits the fallacy of irrelevant person presents an argument against P's reliability as a counter-argument to a claim about $\mathrm{P}^{*} \mathrm{~s}$ reliability. Here is an example.

X: "Miss Limpany is highly reliable as an expert witness. She has a PhD in fire engineering."

Y: "With all due respect, let me just remind the court that every argument that X makes is biased. As we all know, he is paid by the plaintiff to argue this case."

Since Y's argument is about the reliability of the opposing advocate (X), it does not falsify X's claim about Miss Limpany's reliability. Waller (2005, p. 188) has called attention to this kind of fallacy in legal argumentation. As is probably already apparent, the fallacy of irrelevant person is similar to the fallacy of reliability irrelevance. It is also a special case of ignoratio elenchi. 
The fallacy of insufficient degree is committed when the target argument is about P's reliability, but the effect that A has on P's degree of reliability is insufficient to falsify the target claim. The fallacy can be illustrated by the following counter-argument.

X: "I don't think that Jane Jetson is less qualified than the average politician to be Prime Minister."

Y: "Well, she never took a PhD..."

The fact that a politician does not have a PhD may have a small negative effect on the degree to which she can be relied upon to serve as Prime Minister, but the effect of not having a PhD does not make her less qualified than the average politician. After all, the average politician does not have a PhD. The fallacy of insufficient degree is also a special case of ignoratio elenchi. It involves presenting an argument that is unable to falsify the target claim.

Lastly, an error occurs if the effect premise in the extended ad hominem argument concerns a function other than the one in the target claim. The following exchange illustrates this fallacy of irrelevant function:

X: "I would rather trust Bill Clinton than Barack Obama to handle the economic crisis."

Y: "No way! I wouldn't trust Bill Clinton to date my daughter."

\section{Talking about Errors as Fallacies}

As we have seen, ad hominem arguments can go wrong in seven different ways. We have referred to these errors as seven different ad hominem fallacies. Some scholars object to our analysis and claim that some of the errors that we have identified should not be called "fallacies". They accept that we have identified seven different ways in which ad hominem arguments can go wrong, but deny that all of them qualify as "fallacies".

There are different opinions among scholars on how the term fallacy should be used. Some scholars argue, for instance, that an error must be deceptive to qualify as a fallacy (see, e.g., Hitchcock, 2006; Woods, 2007, 
p. 110). We prefer not to employ this psychological criterion. Perhaps some of the errors that we have identified are not very deceptive, but this makes no difference in our analysis. When we talk about an argument as fallacious we make no claim about its psychological effect. It has also been insisted that a fallacious error must occur with some frequency in real arguments (see, e.g., Hitchcock 2006; Woods 2007, p. 110). Some of the errors that we have identified are perhaps not common enough to qualify as fallacies on this view. However, we do not subscribe to this kind of empirical criterion either.

Brinton has identified some ways that ad hominem arguments can go wrong, but he is only prepared to talk about one of them as a fallacy. For Brinton (1995, pp. 216-217), only the kind of error that we have classified as the fallacy of reliability irrelevance comes close to qualifying as a fallacy. When he identifies the kind of error that we have called the fallacy of false attribution he says that this error should not be called a fallacy, as it is not a "logical failure", but merely consists in a false premise (1995, pp. 217-218). This reflects a fundamental difference between Brinton and us. In our approach, where the ad hominem argument is given a deductively valid form, all errors in this argument will manifest themselves as false premises.

\section{Conclusions}

In this paper we have elaborated a framework which can be summarized as follows. Arguments ad hominem note that a person $\mathrm{P}$ has a certain attribute and claim that this attribute affects P's reliability in performing a certain function. $\mathrm{P}$ can be another participant in the discussion, but this is not necessarily the case.

Arguments ad hominem are often used as counter-arguments, but they need not be counter-arguments. In its basic form, an ad hominem argument merely makes a claim about someone's reliability. It need not stand in opposition to some other claim. When an ad hominem argument says that some other claim about the person's reliability is false it becomes an ad hominem argument in the extended form.

By including all kinds of function that a person can be relied upon to fulfill, this framework can be used to analyze and explain a wide range of 
arguments about reliability. It is not limited to the subcategory of arguments about credibility.

As we have seen, our understanding of ad hominem arguments covers positive as well as negative variants. An argument where the attribute pointed out is said to increase reliability is a positive ad hominem, and an argument where the attribute is said to decrease reliability is a negative ad hominem.

Once we give the ad hominem argument a deductively valid form, all errors manifest themselves as false premises. Every possible error either involves a false attribution premise, or a false effect premise, or (in the extended form of the argument) a false rebuttal premise. As we have seen, these premises can be false for various, rather different reasons. We have identified seven grounds of falsity here, and we have suggested that these grounds create, in effect, seven distinct ad hominem fallacies: false attribution, irrelevant attribute, overrated effect, reliability irrelevance, irrelevant person, insufficient degree and irrelevant function.

The presented framework allows questions about when, and to what extent, different kinds of error occur to be addressed rigorously. It also helps to explain why such errors occur. Thus we have seen that the falsity of the effect premise, whether it consists in the fallacy of irrelevant attribute or the fallacy of overrated effect, can be due to a misjudgment of some kind about the function. And when we discussed the relevance of the assumed bundle of attributes we saw that this error can result either from a mistaken assumption about the actual bundle or from a faulty estimate of the effect of an attribute in that bundle.

The framework that has been presented in this article provides a widely applicable tool for approaching and analyzing ad hominem arguments. We recommend that judges use it in their assessment of legal argumentation. As we have seen, ad hominem arguments are often used to attack witness testimony, and we believe that our framework would help judges to identify the various fallacies that are committed in such arguments.

We also hope, of course, that our framework will be used for assessing political argumentation and everyday conversation. We believe, in general, that our framework makes it easier to spot ad hominem fallacies, and easier to avoid them. 


\section{Works Cited}

Bentham, J. The Handbook of Political Fallacies. New York: Harper \& Brothers, 1824/1952.

Brinton, A. "A Rhetorical View of the Ad Hominem." Australasian Journal of Philosophy 63 (1) (1985): 50-63.

Brinton, A. "The Ad Hominem." In Hansen, H. and Pinto, R. (eds.), Fallacies. Classical and Contemporary Readings (pp. 213-222). University Park: Pennsylvania State University Press, 1995.

Copi, I. and Cohen, C. Introduction to Logic. $11^{\text {th }}$ ed. Upper Saddle River: Prentice Hall, 2002.

van Eemeren, F. and Grootendorst, R. "Relevance Reviewed: The Case of Argumentum ad Hominem." Argumentation 6 (2) (1992): 141-159.

Hamblin, Ch. Fallacies. London: Methuen, 1970.

Heise, N. "Deciding not to Decide: Nuremberg and the Ambiguous History of the Tu Quoque Defense." Social Science Research Network. Social Science Electronic Publishing, Inc., 2009. Web. 5 July 2011. < http://ssrn.com/abstract $=1354048>$

Hinman, L. "The Case for Ad Hominem Arguments." Australasian Journal of Philosophy 60 (4) (1982): 338-345.

Hitchcock, D. "Why there is no Argumentum ad Hominem Fallacy." McMaster University, 2006. Web. 1 April 2011. <http://www.humanities.mcmaster. ca/ hitchckd/ adhominemissa.htm >

Johnson, Ch. "Reconsidering the Ad Hominem." Philosophy 84 (2) (2009): 251-266.

Waller, B. Critical Thinking. Consider the Verdict. $5^{\text {th }}$ ed. Upper Saddle River: Prentice Hall, 2005.

Walton, D. "The Ad Hominem Argument as an Informal Fallacy.” Argumentation 1 (3) (1987): 317-331.

Walton, D. Ad Hominem Arguments. Tuscaloosa: University of Alabama Press, 1998.

Walton, D. "Poisoning the Well." Argumentation 20 (3) (2006): 273-307.

Woods, J. "Lightening up on the Ad Hominem." Informal Logic 27 (1) (2007): 109-134.

Woods, J. The Death of Argument. Dordrecht: Kluwer Academic Publishers, 2010.

Yee, S. "The Tu Quoque Argument as a Defence to International Crimes, Prosecution or Punishment." Chinese Journal of International Law 3 (1) (2004): 87-134. 